\title{
The MDR1/ABCB1 gene rs 1045642 polymorphism in colorectal cancer
}

Beata Mrozikiewicz-Rakowska ${ }^{1}$, Marian Malinowski², Piotr Nehring ${ }^{3}$, Joanna Bartkowiak-Wieczorek ${ }^{4}$, Anna Bogacz ${ }^{5}$, Ewa Żurawińska-Grzelka ${ }^{6}$, Przemysław Krasnodębski ${ }^{7}$, Jacek Muszyński³, Tomasz Grzela ${ }^{7}$, Adam Przybyłkowski ${ }^{3}$, Leszek Czupryniak ${ }^{1}$

\author{
'Department of Diabetology and Internal Medicine, Medical University of Warsaw, \\ Warsaw, Poland \\ ${ }^{2} 1^{\text {st }}$ Department of Obstetrics and Gynecology, Medical Centre of Postgraduate \\ Education, Warsaw, Poland \\ ${ }^{3}$ Department of Gastroenterology and Internal Medicine, Medical University \\ of Warsaw, Warsaw, Poland \\ ${ }^{4}$ Laboratory of Experimental Pharmacogenetics, Department of Clinical Pharmacy \\ and Biopharmacy, Poznan University of Medical Sciences, Poznan, Poland \\ ${ }^{5}$ Department of Stem Cells and Regenerative Medicine, Institute of Natural Fibers \\ and Medicinal Plants, Poznan, Poland \\ ${ }^{6}$ Department of Hematology, Oncology and Internal Diseases, Medical University \\ of Warsaw, Warsaw, Poland \\ ${ }^{7}$ Cell Molecular Biology Laboratory, Department of Histology and Embryology, \\ Medical University of Warsaw, Warsaw, Poland
}

Submitted: 11 November 2016

Accepted: 29 June 2017

Arch Med Sci 2020; 16 (1): 112-117

DOI: https://doi.org/10.5114/aoms.2017.70329

Copyright @ 2017 Termedia \& Banach

\section{Abstract}

Introduction: Colorectal cancer (CRC) is one of the most frequently diagnosed tumors in Western countries. CRC is a heterogeneous group of tumors with regards to its molecular pathogenesis and genetic factors. Both genetic variations and anthropometric factors may affect morbidity in CRC patients. The aim of this study was to assess the impact of multidrug resistance 1/ATP-binding cassette sub-family $B$ member 1 gene (MDR1/ABCB1) polymorphism rs 1045642 and general anthropometric factors on the CRC risk. Material and methods: The study included 250 patients who underwent colonoscopy and polypectomy between 2006 and 2013 in a single endoscopy unit in Warsaw, Poland.

Results: The CRC was diagnosed in 50 individuals, and 200 patients were included in the control group. Cases and controls were matched for mean age and sex $(p>0.05)$. Factors that were found to significantly increase the risk of CRC were ulcerative colitis ( $8 / 35$ in the CRC group vs. $8 / 181$ in the control group; $p=0.001)$, family history of CRC (11/33 vs. $26 / 172 ; p=0.05)$, and diabetes mellitus (12/34 vs. 28/170; $p=0.04)$. Allele $T$ of the rs 1045642 polymorphism was more frequently present in CRC cases (in both a co-dominant and recessive model) and in males (in a co-dominant model), although these associations were not statistically significant $(p>0.05)$.

Conclusions: The MDR1/ABCB1 gene polymorphism rs 1045642 may be involved in the pathogenesis of CRC and this relationship may be sex-specific for males. However, further population studies are necessary to assess this relationship.

Key words: colorectal cancer, risk factors, rs 1045642, polymorphism.

\author{
Corresponding author: \\ Beata Mrozikiewicz- \\ Rakowska MD, PhD \\ Department of Diabetology \\ and Internal Medicine \\ Medical University \\ of Warsaw \\ 1 a Banacha St \\ 02-097 Warsaw, Poland \\ Phone: +48 600311399 \\ Fax: +48 225991838 \\ E-mail: rakowskab123@ \\ gmail.com
}




\section{Introduction}

Colorectal cancer (CRC) is one of the most frequently diagnosed neoplasms in Western countries [1] and is estimated to be the main cause of cancer-related death [2]. The average risk of developing CRC in the general population is about $6 \%$ [3]. Regrettably, the first diagnosis of CRC typically occurs when it is already in its most advanced stage (i.e., in $>30 \%$ of cases), and often with metastases (in $\sim 18 \%$ of rectal cancer cases and in $\sim 20-25 \%$ of colon cancer cases) $[2,4,5]$.

The CRCs are a heterogeneous group of cancers with respect to their molecular backgrounds. The pathogenesis of CRC involves many different processes that violate the integrity of the cell genome (from chromosomal and microsatellite instability to abnormal methylation and DNA repair) [6-9]. Unfortunately, the diagnosis of CRC remains difficult as its symptoms depend on the localization and can be easily overlooked by patients (e.g., occult bleeding) [2]. Colonoscopy is still the gold standard of CRC diagnosis; it allows for both diagnostics (tumor localization, histopathology) and treatment of the tumor in its early stages (such as polyp removal) [10-12].

Some previous studies have shown strong correlations between particular gene mutations (such as MUTYH mutations) and CRC, with reports that about $30 \%$ of CRC cases are inherited [2]. In this study, we focused on one member of the transporter family of proteins, P-glycoprotein $(\sim 170 \mathrm{kDa})$, which is encoded by the MDR1/ $A B C B 1$ gene (multidrug resistance 1/ATP-binding cassette sub-family $B$ member 1) [13-16]. P-glycoprotein is an active (ATP-dependent) transporter of xenobiotics (mainly large hydrophobic proteins) [16-20]. Enterocytes spanning the whole digestive tract contain P-glycoprotein, but its largest aggregation is situated at the end of the digestive tract, specifically in the colorectal region $[19,20]$.

The participation of P-glycoprotein in carcinogenesis and its role in drug resistance to chemotherapy are well documented [21-28]. Animal models have confirmed the participation of P-glycoprotein in the carcinogenesis of not only CRCS, but also breast and liver cancers [29-31]. In addition, a link between the MDR1/ABCB1 gene and the $W n t / \beta$-catenin signaling cascade has been found, the latter being the most encountered dysfunction in rare cases of inherited CRC [2]. Moreover, it has been observed in vitro that MDR1/ $A B C B 1$ gene expression occurs in cells with P53 mutations (P53 mutations are detected in $50 \%$ of CRC cases) [32-35].

$M D R 1 / A B C B 1$ gene analysis reveals the existence of 28 exons containing 48 polymorphic variants or single-nucleotide polymorphisms (SNPs) that might contribute to interindividual variability in the function of P-glycoprotein [36]. One of the three most common polymorphisms occurs in the $26^{\text {th }}$ exon (RefSNP ID: rs1045642), while others are present in the $21^{\text {st }}$ exon (RefSNP ID: rs2032582) and in the $12^{\text {th }}$ exon (RefSNP ID: rs1128503) [37]. Previous studies have reported links between the ABCB1 C3435T (rs1045642) polymorphism with an increased risk of developing kidney epithelial tumor and acute lymphoblastic leukemia [38, 39]. The rs 1045642 polymorphism (a synonymous sequence variant in which there is no resulting change to the encoded amino acid) affects both the expression of the MDR1 gene and the activity of P-glycoprotein.

The relationship between the genetic variants (CC, CT, or TT) of the rs1045642 polymorphism and CRC diagnosis is not clear [40-42]. However, the CC genotype may determine proper immunity in the digestive tract, as evidenced by an increased frequency of this genotype in regions with less developed medical care and increased exposure to threatening digestive tract infections (i.e., $\sim 83 \%$ in Ghana vs. $\sim 25 \%$ in Poland) $[42,43]$.

Therefore, the aim of this study was to assess the impact of the MDR1/ABCB1 polymorphism (rs1045642) on the risk of CRC and to assess any general anthropometric factors involved in its development.

\section{Material and methods}

The study included 250 patients hospitalized in the Department of Gastroenterology and Metabolic Diseases, Medical University of Warsaw (which was divided into the Department of Internal Diseases and Diabetology and the Department of Gastroenterology and Internal Medicine in 2015) and the Department of Hematology, Oncology and Internal Diseases, Medical University of Warsaw. The selection criteria for inclusion in the study were patients who underwent both a colonoscopy and polypectomy in a single endoscopy unit between 2006 and 2013 for reasons other than oncologic surveillance after CRC. All patients included in the study underwent a detailed survey to deduce the general risk factors, concomitant diseases, family history, and anthropometric measurements. A histological examination of polyp specimens was performed and genetic information was obtained from a blood sample. Histological examinations were performed in the Medical University of Warsaw; CRC was diagnosed by histological examination using the established $\mathrm{WHO}$ clinical TNM criteria.

The CRC was diagnosed in 50 individuals (forming the study group), and 200 patients without CRC diagnosis were included in the control group. Cases and controls were manually matched based on mean age and sex. 
Patient peripheral blood samples were collected into $5 \mathrm{ml}$ tubes with EDTA anticoagulant. Genetic material isolation was carried out using Syngen Blood/Cell DNA MiniKiT (Syngen Biotech Sp. z o.o.) technique. In order to detect the MDR1/ABCB1 polymorphism (rs1045642) and establish allele distribution, the light SNP assay with real-time PCR were used using the LightCycler 480 instrument in the Laboratory of Experimental Pharmacogenetics, Department of Clinical Pharmacy and Biopharmacy, Poznan University of Medical Sciences, Poland.

The study was approved by the Ethics Committee of the Medical University of Warsaw.

\section{Statistical analysis}

Statistical calculations were performed using Statistica 10 PL (StatSoft Inc. 2011) software. A $\chi^{2}$ test was used to assess qualitative variables. To assess quantitative predictors for normal and abnormal distribution of variables, Student's $t$-test and the Mann-Whitney $U$ test were used, respectively. Normal distribution of variables was defined based on fulfilling the hypothesis of a normal distribution for both groups in the Shapiro-Wilk, Kolmogorov-Smirnov, and Lilliefors tests. A univariate logistic regression was performed for quantitative predictors and in grouping variables when statistical significance was present. The univariate logistic regression analysis was performed with an online program (Logistic Regression by John C. Pezzullo, Version 05.07.20, http://statpages.org/logistic.html). The genetic associations were calculated with the online Asso-test (http://www.ekstroem. com/assotest/assotest.html). The statistical significance level was set at $\alpha=0.05$. Missing data were removed in pairs for statistical analysis.

\section{Results}

The characteristics of the study group are presented in Table I. Cases and controls were age- and sex-matched, so there were no significant differences in these two variables between groups $(p>0.05)$. Statistical analysis showed no differences between groups with respect to the following anthropometric features: mean weight, mean height, mean body mass index (BMI) value, mean hip circumference, and mean waist-hip ratio (WHR). Waist circumference was higher in the study group compared to controls; however, the relationship was not significant and may be biased due to the missing data.

For the nonparametric variables, we found no differences between groups with respect to the following features: tobacco smoking (current, past, and passive); oral contraceptive intake; liver cirrhosis; alcoholic liver disease; toxic liver injury; viral hepatitis; hypertension; congestive heart failure; chronic renal disease; colonic polyps or family history of colonic polyps; familial adenomatous polyposis; hereditary nonpolyposis colorectal cancer; diverticulosis or family history of diverticulosis; hemorrhoids; family history of ulcerative colitis; Crohn's disease (CD); family history of lung, breast, prostate, stomach, or thyroid gland cancers; weight loss in the last 6 months; diarrhea; and fresh blood in stool. We also found no differences in the intake of glucocorticoids, hypolipidemic drugs, or aspirin between groups.

The use of non-steroidal anti-inflammatory drugs (NSAIDs) was more frequently reported in the control group (11/34 in the study group vs. $99 / 97$ in the control group; $p=0.002$ ). Constipation was also more frequently reported in the control group (7/27 vs. $86 / 109 ; p=0.01)$. Ulcerative colitis ( $8 / 35$ vs. $8 / 181 ; p=0.001$, odds ratio (OR) $=5.17 ; 95 \%$ confidence interval $(\mathrm{Cl}): 1.82-14.70)$ and positive family history of CRC (11/33 vs. 26/172; $p=0.05$; OR $=2.25 ; 95 \% \mathrm{Cl}: 0.99-4.90)$ were more frequent in the study group.

Diabetes (12/34 vs. 28/170; $p=0.04)$ increased the risk of $\mathrm{CRC} 2.14$-fold $(\mathrm{OR}=2.14 ; 95 \% \mathrm{Cl}$ : 0.99

Table I. Characteristics of the study groups

\begin{tabular}{|lccc|}
\hline Parameter & Study group (CRC cases) & Control group & P-value \\
\hline Total number & 50 & 200 & - \\
\hline Female/male (\%) & $40 / 60$ & $63 / 57$ & 0.70 \\
\hline Age, mean \pm SD [years] & $65.95 \pm 13.66$ & $72.15 \pm 15.83$ & 0.94 \\
\hline Weight, mean \pm SD $[\mathrm{kg}]$ & $73.70 \pm 13.37$ & $166.88 \pm 9.85$ & 0.56 \\
\hline Height, mean \pm SD $[\mathrm{cm}]$ & $167.98 \pm 9.63$ & $25.84 \pm 5.11$ & 0.54 \\
\hline Body mass index, mean \pm SD $\left[\mathrm{kg} / \mathrm{m}^{2}\right]$ & $26.10 \pm 4.38$ & $85.63 \pm 14.92$ & 0.77 \\
\hline Waist circumference, mean \pm SD [cm] & $92.45 \pm 19.04$ & $95.71 \pm 13.04$ & 0.42 \\
\hline Hip circumference, mean \pm SD $[\mathrm{cm}]$ & $98.56 \pm 16.93$ & $0.90 \pm 0.17$ & 0.14 \\
\hline WHR, mean \pm SD & $0.98 \pm 0.29$ & & \\
\hline
\end{tabular}

$C R C$ - colorectal cancer, WHR - waist-hip ratio, SD - standard deviation. 
4.63). In both cohorts, diabetes mellitus (DM) type 2 was the dominant diabetes subtype.

Past hormone replacement therapy was observed more frequently in the study group, but this difference was not statistically significant $(31 / 23$ vs. $20 / 79 ; p=0.06$ ). Family histories of $C D$ and pancreatic cancer were observed more frequently in the study group than in the control group (1/44 vs. $0 / 200 ; p=0.03$ and $2 / 43$ vs. $0 / 197 ; p=0.003$, respectively).

The frequency of alleles in the control group was similar to the diversity of the rs 1045642 polymorphism in the European population based on the NCBI db SNP Short Genetic Variation allele frequencies (HapMap-CEU ss35072275: C/C 0.15; C/T 0.56; T/T 0.29 vs. controls, $p>0.05)$.

In the present study, allele T of SNP rs1045642 was observed slightly more frequently in the study group; however, this finding was not statistically significant. This relationship between the $T$ allele and CRC was most visible in the co-dominant and recessive models. An association between the T allele and male sex was also revealed in a co-dominant model. The associations of SNP rs1045642 in the study and control groups are presented in Table II.

\section{Discussion}

The general risk factors of CRC are well known; among them, obesity plays an important role [44]. The correlation between gender and BMI in the risk of CRC has been noted in the literature, and it primarily concerns men [45-47]. This difference may be due to hormonal differences between sexes and the resultant changes in the distribution of fat tissue within the body (e.g. abdominal obesity in men) $[44,48]$.
In this study, we observed a correlation between waist circumference and risk of CRC. In 2014, Brandstedt et al. explored the correlation between anthropometric factors and CRC caused by KRAS and BRAF mutations [44]. They observed that high weight, hip, waist, WHR, and BMI values were associated with an increased risk of BRAF wild type tumors, but none of the anthropometric factors were associated with risk of BRAF-mutated CRC, either in the overall or in the sex-stratified analysis. While all anthropometric measures (except height) were associated with an increased risk of KRAS-mutated tumors, only BMI was associated with an increased risk of KRAS wild type tumors overall [44].

When analyzing a German population, Sainz et al. confirmed that men carrying the $C$ allele of the rs1045642 polymorphism are less prone to develop $C R C(O R=0.85,95 \% \mathrm{Cl}$ : 0.74-0.97, per allele), whereas men with the minor $G$ allele of the rs9282564 polymorphism had an increased risk of CRC [49]. It is suggested that these variants may influence the ABCB1-mediated estrogen efflux from the colonic epithelial cells and therefore modify the risk for CRC. However, the authors claimed that as P-glycoprotein is a transporter of several substances, the effects may not necessarily be solely attributable to altered estrogen transport, especially in men [49].

In contrast, Martinelli et al. observed that the MDR1/ABCB1 polymorphisms rs1128503, rs2032582, and rs1045642 had no impact on CRC risk [50]. However, the study described an association of $M D R 1 / A B C B 1$ with $C R C$ localization in the sigmoid colon and an influence on gender ratio in CRC patients [50]. These results confirm sex-specificity of MDR1/ABCB1 in CRC patients, supporting the data presented in this study.

Table II. Associations between rs1045642 single nucleotide (SNP rs1045642 (C3435T)) polymorphisms and colorectal cancer

\begin{tabular}{|c|c|c|c|c|c|c|c|}
\hline \multirow[t]{3}{*}{ Study group } & \multicolumn{3}{|c|}{ Genotype } & \multicolumn{3}{|c|}{$\begin{array}{c}\text { OR } \\
(95 \% \mathrm{Cl}) \\
P \text {-value }\end{array}$} & \multirow[t]{3}{*}{$\begin{array}{c}\chi^{2} \\
P \text {-value }\end{array}$} \\
\hline & CC & CT & TT & \multirow{2}{*}{$\begin{array}{l}\text { Dominant } \\
\text { CT/TT vs. CC }\end{array}$} & \multirow{2}{*}{$\begin{array}{l}\text { Co-dominant } \\
\text { TT vs. CT = } \\
\text { CT vs. CC }\end{array}$} & \multirow{2}{*}{$\begin{array}{l}\text { Recessive } \\
\text { TT vs. CC/CT }\end{array}$} & \\
\hline & $\begin{array}{c}\% \\
n / N\end{array}$ & $\begin{array}{c}\% \\
n / N\end{array}$ & $\begin{array}{c}\% \\
n / N\end{array}$ & & & & \\
\hline Cases & $\begin{array}{l}18.00 \\
9 / 50\end{array}$ & $\begin{array}{l}50.00 \\
25 / 50\end{array}$ & $\begin{array}{l}32.00 \\
16 / 50\end{array}$ & $\begin{array}{c}1.48 \\
(0.67-3.26) \\
0.319 \\
\end{array}$ & $\begin{array}{c}1.351 \\
(0.94-2.41) \\
0.082 \\
\end{array}$ & $\begin{array}{c}1.56 \\
(0.95-3.74) \\
0.078 \\
\end{array}$ & $\begin{array}{l}3.349 \\
0.187\end{array}$ \\
\hline $\begin{array}{l}\text { Cases, } \\
\text { females }\end{array}$ & $\begin{array}{l}20.00 \\
4 / 20\end{array}$ & $\begin{array}{l}55.00 \\
11 / 20\end{array}$ & $\begin{array}{l}25.00 \\
5 / 20\end{array}$ & $\begin{array}{c}1.21 \\
(0.36-4.04) \\
0.751\end{array}$ & $\begin{array}{c}1.30 \\
(0.61-2.78) \\
0.498\end{array}$ & $\begin{array}{c}1.58 \\
(0.50-5.01) \\
0.449\end{array}$ & $\begin{array}{l}0.587 \\
0.746\end{array}$ \\
\hline Cases, males & $\begin{array}{l}16.66 \\
5 / 30\end{array}$ & $\begin{array}{l}46.67 \\
14 / 30\end{array}$ & $\begin{array}{l}36.67 \\
11 / 30\end{array}$ & $\begin{array}{c}1.71 \\
(0.60-4.87) \\
0.300\end{array}$ & $\begin{array}{c}1.64 \\
(0.90-2.97) \\
0.098\end{array}$ & $\begin{array}{c}2.06 \\
(0.87-4.90) \\
0.107\end{array}$ & $\begin{array}{l}2.884 \\
0.237\end{array}$ \\
\hline $\begin{array}{l}\text { Control } \\
\text { group }\end{array}$ & $\begin{array}{c}24.50 \\
49 / 200\end{array}$ & $\begin{array}{c}55.50 \\
111 / 200\end{array}$ & $\begin{array}{c}20.00 \\
40 / 200\end{array}$ & - & - & - & \\
\hline
\end{tabular}

$\mathrm{Cl}$ - confidence interval, $n$ - number of alleles, $N$ - total number of alleles, OR - odds ratio, SNP-single nucleotide polymorphism. 
A Danish population based study by Kopp et al. showed that the MDR1/ABCB1 rs1045642 and $A B C G 2$ rs2231137 haplotypes were associated with a risk of CRC, and that rs1045642 interacted with intake of cereals and fiber [51]. Meanwhile, Zhao et al. provided evidence that rs1045642 is not associated with an increased risk of CRC in a study involving 11,339 individuals in the Asian and Caucasian population [52]. A meta-analysis of 39 case-control studies by Sheng et al. confirmed the impact of this polymorphism on the overall risk of cancer in TT carriers compared to CT and CC genotypes; however, the results suggested a stronger association with hematologic malignancies [53].

In this study, we more frequently observed the presence of ulcerative colitis in patients with CRC compared to the control group. Inflammatory bowel diseases (IBD), including ulcerative colitis and $C D$, are known to increase the risk of CRC. Indeed, according to a meta-analysis performed in 2013 by Johnson et al., IBD increases the risk of CRC 2.93-fold [54]. This meta-analysis also showed that the development of CRC in first-degree relatives is associated with an increased CRC risk of up to 1.79-fold [54]. Likewise, we found that a positive family history of CRC was observed more frequently in CRC patients compared to the control group. Finally, diabetes was observed more often in CRC patients than in the control group, which is in accordance with previous studies showing that individuals with diabetes are at a $27 \%$ higher risk of developing CRC [55].

In conclusion, our study indicates that the $\mathrm{T}$ allele of rs 1045642 is more frequent in males with CRC. This suggests that the MDR1/ABCB1 gene polymorphism rs 1045642 may be involved in the pathogenesis of CRC in a sex-specific manner. Further population studies are necessary to explore this association.

\section{Conflict of interest}

The authors declare no conflict of interest.

\section{References}

1. Ferlay J, Parkin DM, Steliarova-Foucher E. Estimates of cancer incidence and mortality in Europe in 2008. Eur J Cancer 2010; 46: 765-81.

2. De Rosa M, Pace U, Rega D, et al. Genetics, diagnosis and management of colorectal cancer (Review). Oncol Rep 2015; 34: 1087-96.

3. Landis SH, Murray T, Bolden S, Wingo PA. Cancer statistics, 1998. CA Cancer J Clin 1998; 48: 6-29.

4. Van Leersum NJ, Snijders HS, Henneman D, et al. The Dutch surgical colorectal audit. Eur J Surg Oncol 2013; 39: 1063-70.

5. Leufkens AM, van den Bosch MA, van Leeuwen MS, Siersema PD. Diagnostic accuracy of computed tomog- raphy for colon cancer staging: a systematic review. Scand J Gastroenterol 2011; 46: 887-94.

6. Goel A, Nagasaka T, Arnold CN, et al. The CpG island methylator phenotype and chromosomal instability are inversely correlated in sporadic colorectal cancer. Gastroenterology 2007; 132: 127-38.

7. Sideris M, Papagrigoriadis S. Molecular biomarkers and classification models in the evaluation of the prognosis of colorectal cancer. Anticancer Res 2014; 34: 2061-8.

8. Pino MS, Chung DC. The chromosomal instability pathway in colon cancer. Gastroenterology 2010; 138: 2059-72.

9. Boland CR, Goel A. Microsatellite instability in colorectal cancer. Gastroenterology 2010; 138: 2073-87.

10. Barret M, Boustiere C, Canard JM, et al. Factors associated with adenoma detection rate and diagnosis of polyps and colorectal cancer during colonoscopy in France: results of a prospective, nationwide survey. PLoS One 2013; 8: e68947.

11. Kaminski MF, Regula J, Kraszewska E, et al. Quality indicators for colonoscopy and the risk of interval cancer. N Engl J Med 2010; 362: 1795-803.

12. Zauber AG, Winawer SJ, O’Brien MJ, et al. Colonoscopic polypectomy and long-term prevention of colorectal-cancer deaths. N Engl J Med 2012; 366: 687-96.

13. Greiner B, Eichelbaum M, Fritz P, et al. The role of intestinal P-glycoprotein in the interaction of digoxin and rifampin. J Clin Invest 1999; 104: 147-53.

14. Leslie EM, Deeley RG, Cole SP. Multidrug resistance proteins: role of P-glycoprotein, MRP1, MRP2, and BCRP (ABCG2) in tissue defense. Toxicol Appl Pharmacol 2005; 204: 216-37.

15. Hrycyna CA, Airan LE, Germann UA, Ambudkar SV, Pastan I, Gottesman MM. Structural flexibility of the linker region of human P-glycoprotein permits ATP hydrolysis and drug transport. Biochemistry 1998; 37: 13660-73.

16. Higgins CF. ABC transporters: from microorganisms to man. Annu Rev Cell Biol 1992; 8: 67-113.

17. Ambudkar SV, Dey S, Hrycyna CA, Ramachandra M, Pastan I, Gottesman MM. Biochemical, cellular, and pharmacological aspects of the multidrug transporter. Annu Rev Pharmacol Toxicol 1999; 39: 361-98.

18. Sarkadi B, Homolya L, Szakacs G, Varadi A. Human multidrug resistance $A B C B$ and $A B C G$ transporters: participation in a chemoimmunity defense system. Physiol Rev 2006; 86: 1179-236.

19. Thiebaut F, Tsuruo T, Hamada H, Gottesman MM, Pas$\tan$ I, Willingham MC. Cellular localization of the multidrug-resistance gene product P-glycoprotein in normal human tissues. Proc Natl Acad Sci USA 1987; 84: 7735-8.

20. Johnstone RW, Ruefli AA, Smyth MJ. Multiple physiological functions for multidrug transporter P-glycoprotein? Trends Biochem Sci 2000; 25: 1-6.

21. Atalay C, Demirkazik A, Gunduz U. Role of $A B C B 1$ and $A B C C 1$ gene induction on survival in locally advanced breast cancer. J Chemother 2008; 20: 734-9.

22. Balcerczak E, Panczyk M, Piaskowski S, Pasz-Walczak G, Salagacka A, Mirowski M. ABCB1/MDR1 gene polymorphisms as a prognostic factor in colorectal cancer. Int J Colorectal Dis 2010; 25: 1167-76.

23. Campa D, Sainz J, Pardini B, et al. A comprehensive investigation on common polymorphisms in the MDR1/ ABCB1 transporter gene and susceptibility to colorectal cancer. PLoS One 2012; 7: e32784.

24. Panczyk M, Balcerczak E, Piaskowski S, Jamroziak K, Pasz-Walczak G, Mirowski M. ABCB1 gene polymorphisms and haplotype analysis in colorectal cancer. Int J Colorectal Dis 2009; 24: 895-905. 
25. Atalay C, Deliloglu G, I, Irkkan C, Gunduz U. Multidrug resistance in locally advanced breast cancer. Tumour Bio 2006; 27: 309-18.

26. Germann UA, Chambers TC, Ambudkar SV, Pastan I, Gottesman MM. Effects of phosphorylation of P-glyco protein on multidrug resistance. J Bioenerg Biomembr 1995; 27: 53-61.

27. Gottesman MM, Pastan I, Ambudkar SV. P-glycoprotein and multidrug resistance. Curr Opin Genet Dev 1996; 6: 610-7.

28. Shitara K, Matsuo K, Ito S, et al. Effects of genetic poly morphisms in the ABCB1 gene on clinical outcomes in patients with gastric cancer treated by second-line chemotherapy. Asian Pac J Cancer Prev 2010; 11: 447-52.

29. Mochida Y, Taguchi K, Taniguchi S, et al. The role of P-glycoprotein in intestinal tumorigenesis: disruption of mdr1a suppresses polyp formation in $\mathrm{Apc}(\mathrm{Min} /+)$ mice. Carcinogenesis 2003; 24: 1219-24.

30. Kankesan J, Vanama R, Yusuf A, et al. Effect of PSC 833, an inhibitor of P-glycoprotein on N-methyl-N-nitrosourea induced mammary carcinogenesis in rats. Carcinogenesis 2004; 25: 425-30.

31. Kankesan J, Yusuf A, Laconi E, et al. Effect of PSC 833 , an inhibitor of P-glycoprotein, on 1,2-dimethylhydrazine-induced liver carcinogenesis in rats. Carcinogenesis 2003; 24: 1977-84.

32. Nguyen KT, Liu B, Ueda K, Gottesman MM, Pastan I, Chin KV. Transactivation of the human multidrug resis tance (MDR1) gene promoter by p53 mutants. Oncol Res 1994; 6: 71-7.

33. Chin KV, Ueda K, Pastan I, Gottesman MM. Modulation of activity of the promoter of the human MDR1 gene by Ras and p53. Science 1992; 255: 459-62.

34. Greenblatt MS, Bennett WP, Hollstein M, Harris CC. Mutations in the p53 tumor suppressor gene: clues to cancer etiology and molecular pathogenesis. Cancer Res 1994; 54: 4855-78.

35. Lehman TA, Greenblatt M, Bennett WP, Harris CC. Mu tational spectrum of the p53 tumor suppressor gene: clues to cancer etiology and molecular pathogenesis. Drug Metab Rev 1994; 26: 221-35.

36. Kroetz DL, Pauli-Magnus C, Hodges LM, et al. Sequence diversity and haplotype structure in the human $A B C B 1$ (MDR1, multidrug resistance transporter) gene. Pharmacogenetics 2003; 13: 481-94.

37. Cascorbi I, Gerloff T, Johne A, et al. Frequency of single nucleotide polymorphisms in the P-glycoprotein drug transporter MDR1 gene in white subjects. Clin Pharmacol Ther 2001; 69: 169-74.

38. Siegsmund M, Brinkmann U, Schaffeler E, et al. Association of the P-glycoprotein transporter MDR1(C3435T) polymorphism with the susceptibility to renal epithelial tumors. J Am Soc Nephrol 2002; 13: 1847-54

39. Jamroziak K, Mlynarski W, Balcerczak E, et al. Functional C3435T polymorphism of MDR1 gene: an impact on genetic susceptibility and clinical outcome of childhood acute lymphoblastic leukemia. Eur J Haematol 2004; 72: 314-21.

40. Wang F, Huang Z, Zheng K, Zhao H, Hu W. Two SNPs of ATP-binding cassette $\mathrm{B} 1$ gene on the risk and prognosis of colorectal cancer. Int J Clin Exp Pathol 2015; 8: 3083-9.

41. De ludicibus S, De Pellegrin A, Stocco G, Bartoli F, Bussani R, Decorti G. ABCB1 gene polymorphisms and expression of P-glycoprotein and long-term prognosis in colorectal cancer. Anticancer Res 2008; 28: 3921-8.

42. Kurzawski M, Drozdzik M, Suchy J, et al. Polymorphism in the P-glycoprotein drug transporter MDR1 gene in colon cancer patients. Eur J Clin Pharmacol 2005; 61: 389-94.

43. Schaeffeler E, Eichelbaum M, Brinkmann U, et al. Frequency of C3435T polymorphism of MDR1 gene in African people. Lancet 2001; 358: 383-4.

44. Brandstedt J, Wangefjord S, Nodin B, et al. Associations of anthropometric factors with KRAS and BRAF mutation status of primary colorectal cancer in men and women: a cohort study. PLoS One 2014; 9: e98964.

45. Moore LL, Bradlee ML, Singer MR, et al. BMI and waist circumference as predictors of lifetime colon cancer risk in Framingham Study adults. Int J Obes Relat Metab Disord 2004; 28: 559-67.

46. Renehan AG, Tyson M, Egger M, Heller RF, Zwahlen M. Body-mass index and incidence of cancer: a systematic review and meta-analysis of prospective observational studies. Lancet 2008; 371: 569-78.

47. Maclnnis RJ, English DR, Hopper JL, Gertig DM, Haydon AM, Giles GG. Body size and composition and colon cancer risk in women. Int J Cancer 2006; 118: 1496-500.

48. Krotkiewski M, Bjorntorp P, Sjostrom L, Smith U. Impact of obesity on metabolism in men and women. Importance of regional adipose tissue distribution. J Clin Invest 1983; 72: 1150-62.

49. Sainz J, Rudolph A, Hein R, et al. Association of genetic polymorphisms in ESR2, HSD17B1, ABCB1, and SHBG genes with colorectal cancer risk. Endocr Relat Cancer 2011; 18: 265-76.

50. Martinelli M, Scapoli L, Cura F, et al. Colorectal cancer susceptibility: apparent gender-related modulation by ABCB1 gene polymorphisms. J Biomed Sci 2014; 21: 89.

51. Kopp TI, Andersen V, Tjonneland A, Vogel U. Polymorphisms in ATP-binding cassette transporter genes and interaction with diet and life style factors in relation to colorectal cancer in a Danish prospective case-cohort study. Scand J Gastroenterol 2015; 50: 1469-81.

52. Zhao L, Li K, Li W, Yang Z. Association between the C3435T polymorphism of ABCB1/MDR1 gene (rs1045642) and colorectal cancer susceptibility: a meta-analysis based on 11,339 subjects. Tumour Biol 2013; 34: 1949-57.

53. Sheng X, Zhang L, Tong N, et al. MDR1 C3435T polymorphism and cancer risk: a meta-analysis based on 39 case-control studies. Mol Biol Rep 2012; 39: 7237-49.

54. Johnson CM, Wei C, Ensor JE, et al. Meta-analyses of colorectal cancer risk factors. Cancer Causes Control 2013; 24: 1207-22.

55. González N, Prieto I, del Puerto-Nevado L, et al. 2017 update on the relationship between diabetes and colorectal cancer: epidemiology, potential molecular mechanisms and therapeutic implications. Oncotarget 2017; 8: $18456-85$. 